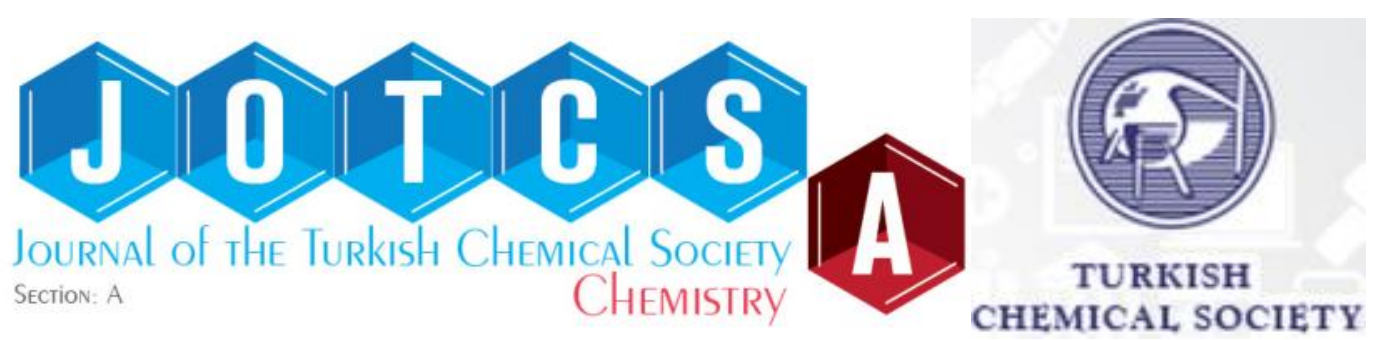

\title{
Analysis of Chemical Compositions of 15 Different Cold-Pressed Oils Produced in Turkey: A Case Study of Tocopherol and Fatty Acid Analysis
}

\author{
Veysel U. Celenk1 ${ }^{(D)}$, Z. Pinar Gumus ${ }^{1,2 *}$, Zeliha Ustun Argon ${ }^{3,4}(D$, Mevlut \\ Buyukhelvacigil $^{4}$, Ercument Karasulu1,5 \\ ${ }^{1}$ Ege University, Drug Research and Pharmacokinetic Development and Applied Center, \\ ARGEFAR, 35100, Bornova, Izmir, Turkey \\ 2 Ege University, Institute on Drug Abuse, Toxicology and Pharmaceutical Science, BATI \\ INSTITUTE, 35100, Bornova, Izmir, Turkey \\ ${ }^{3}$ Necmettin Erbakan University, Eregli Faculty of Engineering and Natural Sciences, \\ 42310 Eregli, Konya \\ ${ }^{4}$ Zade Vital Pharmaceuticals Inc., KOS Güzel Konak Sok. 42300 Karatay, Konya, Turkey \\ ${ }^{5}$ Ege University, Faculty of Pharmacy, Department of Pharmaceutical Technology, 35040, \\ Bornova, Izmir, Turkey
}

\begin{abstract}
Many people tend to prefer natural foods and supplements nowadays. Considering this tendency, this study assessed the most significant in quality and purity parameters tocopherol and fatty acid compositions of cold-pressed oils, namely black cumin, sesame, sunflower, poppy, pomegranate, nettle, pumpkin, grape, safflower, flax, canola seed, wheat germ, peanut, hazelnut, and walnut. This study deals with the sample preparation and validation of tocopherols using an HPLC-FLD method for simultaneous determination of $a-\beta-\gamma^{-}$, and $\delta$-tocopherols, and analysis of fatty acid methyl esters (FAME) with using GC-FID. The validated HPLC method was applied for the tocopherols' analysis and measurement uncertainty was calculated for tocopherols and some fatty acids. The obtained data were evaluated by using principal component analysis to show the relationship between quality parameters and seed oils. Wheat germ, hazelnut, safflower, and sunflower oils have the highest tocopherol contents respectively with a predominance of a-tocopherol. Seed oils' fatty acid compositions were classified according to proportions of oleic, linoleic, and other fatty acids. This study shows that the evaluated seeds are valuable sources of natural antioxidants and some specific and polyunsaturated fatty acids. The applied method can also be helpful for the industry to obtain quality analysis approach.
\end{abstract}

Keywords: Seed oils, tocopherols, FAME, method validation, HPLC, PCA.

Submitted: 17 Aug. 2017. Accepted: 10 Oct. 2017.

Cite this: Celenk V, Gumus Z, Ustun Argon Z, Buyukhelvacigil M, Karasulu E. Analysis of Chemical Compositions of 15 Different Cold-Pressed Oils Produced in Turkey: A Case Study of Tocopherol and Fatty Acid Analysis. "Journal of the Turkish Chemical Society, Section A: Chemistry. 2018; 5(1):1-18.

DOI: http://doi.org/10.18596/jotcsa.335012.

*Corresponding author. E-mail: z.pinar.gumus@gmail.com. Phone: +90 (232) 390 1646, Fax: +90 (232) 3901694. 


\section{INTRODUCTION}

Cold-pressed seed oils have health-beneficial factors and significant chemical properties and some consumers tend to prefer natural, nutritional, and safe food supplements for preventing illnesses, maintaining internal and external wellness. There are some different extraction techniques to obtain oil from oily fruits and seeds, these being organic solvent extraction, screw-press or hydraulic press, the cold-press technique does not require an external heat either organic solvent (1-4). The oil was purified by settling, filtering, and centrifuging only (5). Cold-pressing is simple, ecologically friendly, and needs less energy for the process. If the cold-press method is compared with the other extraction methods, especially with supercritical carbon dioxide $\left(\mathrm{CO}_{2}\right)$ extraction, with regards to the investment's cost of the equipment and the cost of the last product, the cold press method is found less expensive and needs less labor than other extraction techniques $(6,7)$. Therefore, high-quality oils can be obtained by cold-pressing technique with lower costs and this method can be used for commercial production. Amounts of oil were shown to have final volume differences according to extraction techniques. The oil yield of the coldpressing technique is lower than hot-pressing, solvent, and supercritical carbon dioxide $\left(\mathrm{CO}_{2}\right)$ extraction (8). In recent years, interest and demand of consumers to use coldpressed oil have increased because cold-pressed oils are natural, nutritional, and safe food products $(9,10)$. Cold-pressed seed oils have great dietary value, specific sensory properties, health-beneficial factors and significant chemical properties because neither heat treatment nor any organic solvent were used to obtain oil from the raw material (3, 10). Thus, natural antioxidants and beneficial phytochemicals such as tocopherols, fatty acids, sterols and antioxidant phenolic compounds are protected at higher levels in cold pressed oils (11-14).

The quality and processing of seed oils are the main determinants of fatty acid composition and tocopherol content that support the reduced risk of coronary heart disease, geriatric diseases, anti-inflammatory and anti-proliferative effects on the types of cancer (15-17).

Tocopherols are important lipo-soluble antioxidants for the protection of human health because they preserve the oil against to lipid oxidation and they are effective against to the activities causing oxidative stress (18-20). When a natural tocopherol is compared to synthetic ones, especially a-tocopherol is superior for radical chain-breaking. It is a lipidsoluble antioxidant and increase the resistance of LDL to oxidation. a-tocopherol, $\mathrm{Y}^{-}$ tocopherol has specific biologic activity that potentially protects against to the chronic diseases, such as inflammation (21). 
The seed oils have rich mono-unsaturated and poly-unsaturated fatty acids (PUFA) (22). The human body can produce all fatty acids except linoleic acid and a-linolenic acid which are the simplest members of family of PUFA. PUFA regulate biological functions which range from blood pressure and blood clotting to the correct development and functioning of the brain and nervous system and it also has important role in the composition of all cellular membranes (23-25). Oleic acid, a mono-unsaturated fatty acid, has shown activity in cancer prevention, compared to polyunsaturated fatty acids, making it much less susceptible to oxidation and contributing to the antioxidant action, high stability, and long shelf life because oleic acid has a role in preventing oxidative stress $(26,27)$. It is thought that the reason for the chronic diseases being seen less in societies fed with Mediterranean diets having high oleic acid amount (28).

Because of the above-described and recognized importance of the fatty acid and tocopherol compositions, the main idea of this study is to determine fifteen cold-pressed oils' tocopherol and fatty acid compositions. These were black cumin seed, wheat germ, sesame seed, sunflower seed, poppy seed, pomegranate seed, nettle seed, peanut, pumpkin seed, walnut, hazelnut, grape seed, safflower seed, flax seed, and canola seed oils. For this purpose, the reliable, sensitive, and practical sample preparation methods for tocopherols were developed and validated for designation of the quality of these different cold-pressed oils produced in Turkey. In addition, fatty acid methyl esters (FAME) of cold-pressed seed oils were analyzed. Hence, the results from the present study can be taken and used to classify the quality and purity of cold-pressed oils in the market and also the seed oils which are used as natural supplements. Principal component analysis was applied to find out markers for each seed oil and classified according to composition of the oil.

\section{MATERIAL AND METHOD}

\section{Seed Oil Samples}

Seed samples were obtained from different geographical regions of Turkey where seed production of particular types are concentrated. Table 1 lists and shows the regions where the seeds were collected in Turkey. ZADE cold-pressed oils were produced at cold-pressing plants of the Zade Vital Pharmaceuticals, Inc.

During the cold-press process, the temperature was kept below $40^{\circ} \mathrm{C}$. Neither solvent nor heating process was used to protect physicochemical properties of the oil. The cold-press machine was used by 3-4 kg seed/h capacity depending on the seeds' differences. Settling out the sediments has been done by storing the cold-pressed oil in stainless steel intermediate tanks for one day. The next day, filtration of oil was completed by using $1 \mu \mathrm{m}$ 
pores filtration paper. In the last step, the cold pressed oils were filled into $200 \mathrm{~mL}$ amber glass bottles and kept at $25{ }^{\circ} \mathrm{C}$ and at $60 \%$ relative humidity until the analysis was conducted.

Table 1: Production regions of seeds at Turkey.

\begin{tabular}{cc}
\hline Seeds & Regions \\
\hline Black Cumin Seed & Central Anatolia - Aegean \\
Wheat Germ & Central Anatolia-All regions \\
Sesame Seed & Mediterranean \\
Sunflower Seed & Central Anatolia-All regions \\
Poppy Seed & Central Anatolia - Aegean \\
Pomegranate Seed & Aegean - South eastern Anatolia \\
Nettle Seed & City of Hatay in Mediterranean region \\
Flax Seed & Aegean - Central Anatolia -Black Sea \\
Peanut & South eastern Anatolia \\
Pumpkin Seed & Central Anatolia - All regions \\
Walnut & Central Anatolia -Black Sea \\
Hazelnut & Black Sea \\
Grape Seed & Aegean \\
Safflower Seed & Central Anatolia \\
Canola & Central Anatolia
\end{tabular}

\section{Reagents}

All the reagents were purchased from J.T. Baker, LabScan, and Sigma-Aldrich and they were either chromatographic or analytical grade. Millipore ultrapure water (Type I) was used for all analyses. FAME mix (including 37 fatty acids) (Supelco) was used as a standard for determination of retention time of fatty acids. Tocopherol Set (Merck) was used for calibration and validation as a standard which is including four-vial pack containing $a, \beta$, $Y$, and $\delta$-tocopherols.

\section{Chromatographic conditions}

Chromatographic analyses were carried out on an Agilent HPLC-FLD system using silica columns ( $5 \mu \mathrm{m}$ particle size, L $\times$ I.D. $25 \mathrm{~cm} \times 4.6 \mathrm{~mm}$, LiChrosorb SI 60) for separation and quantification. $290 \mathrm{~nm}$ and $330 \mathrm{~nm}$ were selected as excitation and emission wavelengths, respectively. n-Hexane:2-propanol (99.5:0.5) mixture was used as the mobile phase for tocopherol isomers at a flow rate of $0.8 \mathrm{~mL} / \mathrm{min}$. Sample preparation for tocopherol analysis was done according to a modified method of the American Oil Chemists' Society (AOCS) Lipid Library (29). The cold saponification method was used in the standard method for sample preparation. This method of sample preparation is both long and costly. In this study, oils were prepared with a more practical and inexpensive method. In the 
assay, $0.5 \mathrm{~g}$ of seed oils were dissolved in $10 \mathrm{~mL}$ of hexane then vortexed. $20 \mu \mathrm{L}$ of the homogeneous solution was injected into the HPLC system at $25^{\circ} \mathrm{C}$.

FAME analysis was applied according to COI/T.20/Doc. No 33 for cold-pressed oils (30). Identification of the fatty acids was done according to their retention times. The quantitative analysis was carried out by determination of the area ratio under the relevant peak to the sum of the areas under all the peaks for the fatty acids. FAME analysis was performed with an Agilent 6890 GC-FID system. A Supelco 2560 capillary column (100 m $\times 0.25 \mathrm{~mm}$ ID $\times 0.2 \mu \mathrm{m}$ ) and 1:100 split ratio was used. Inlet and detector temperatures were $250^{\circ} \mathrm{C}$ and $260^{\circ} \mathrm{C}$, respectively. The temperature program was as follows; the oven temperature was held at $140{ }^{\circ} \mathrm{C}$ for $1 \mathrm{~min}$ and then increased to $240{ }^{\circ} \mathrm{C}$ at a rate of 4 ${ }^{\circ} \mathrm{C} / \mathrm{min}$ and held for $5 \mathrm{~min}$.

\section{Preparation of standard and calibration solutions}

Stock solutions $(1000 \mu \mathrm{g} / \mathrm{mL})$ of the tocopherols were prepared in $n$-hexane. The working standard solutions were diluted with $n$-hexane from the stock solutions. Concentration ranges of calibration solutions were $1.25-200.00 \mu \mathrm{g} / \mathrm{mL}$ for all tocopherols. Triplicate injections $(20 \mu \mathrm{L})$ were made for each concentration of tocopherols. The peak areas, the excitation at $290 \mathrm{~nm}$ and the emission at $330 \mathrm{~nm}$ wavelengths were plotted against to the corresponding concentrations to make the calibration graphs, and the linear regression equations were calculated.

The samples were prepared by weighing approximately $0.500 \mathrm{~g}( \pm 0,001 \mathrm{~g})$ of seed oil into a $10 \mathrm{~mL}$ volumetric flask, adding $8 \mathrm{~mL}$ of $\mathrm{n}$-hexane followed by 5 minutes of sonication in ultrasonic bath and then made up to volume to $10 \mathrm{~mL}$ with $\mathrm{n}$-hexane and then sonication was repeated for 5 minutes for tocopherol analyses. The procedure of sample preparation was very practical thus time spent on sample preparation was reduced compared with coldsaponification methods at the AOSC Official Methods (31).

\section{Principal Component Analysis (PCA)}

Principal Component Analysis was executed to show the relationship and differences between seed oils. The multivariate analyses were performed using the MINITAB 15 Statistical Software. The data for all tocopherols and fatty acids were performed using by the PCA (the Ward algorithmic method chemometric methods). The results of PCA were visualized by scores and loading plots. The score plots were made by contact between principal groupings and observations. The loading plots were pointed out the importance of each variable for the analyses, loading plots and were used to explain the relationship between variables. 


\section{RESULTS AND DISCUSSION}

HPLC method coupled with fluorescence detection was developed to make it an available, suitable, and practical procedure for the quality control analysis of tocopherols. The proposed HPLC-FLD method was validated according to the ICH guidelines in terms of some validation parameters (32). The GC-FID standard method was used according to IOC for determination of FAME (30).

\section{Optimization of Chromatographic Conditions}

The mobile phases were optimized within different solvents according to resolution of isomers, peak symmetry, tailing factor, and theoretical plate number. The best separation between the four isomers of tocopherols had been with the use of a LICHROSORB SI 60 column. The best chromatogram was obtained with an isocratic elution of the mobile phase system consisting of $n$-hexane:2-propanol (99.5:0.5) ( $\mathrm{v}: \mathrm{v})$ mobile phase. The excitation and emission wavelengths were selected according to literatures (29-31). The quantification was achieved using a fluorescence detector based on peak area measurement.

\section{Validation of Proposed Methods}

A validation study was carried out for all isomers of tocopherols. The linearity of the HPLCFLD method was assessed by analyzing a series of eight different concentrations for each tocopherol. Table 2 presents the linearity and sensitivity data and statistical parameters for the method including parameters of linear regression equations, coefficients, concentration ranges, standard deviations (SD) and relative standard deviation (RSD \%) of the intercept and the slope. The coefficient values $\left(R^{2} \geq 0.9997\right)$ were shown that regression analysis has had a good linearity and RSD\% of the slope, and intercept values which were found less than $0.10 \%$ and $2.00 \%$, respectively.

The limits of detection (LOD) and limits of quantification (LOQ) were calculated based on signal-to-noise ratio values in according to the $\mathrm{ICH}$ guidelines. The given data in Table 2 has shown that the method is sensitive enough to detect concentrations for the analyzed compounds. 
Table 2: Linearity and sensitivity of proposed HPLC-FLD methods.

\begin{tabular}{lcccc}
\hline & $\begin{array}{c}\text { Alpha } \\
\text { Tocopherols }\end{array}$ & $\begin{array}{c}\text { Beta } \\
\text { Tocopherols }\end{array}$ & $\begin{array}{c}\text { Gamma } \\
\text { Tocopherols }\end{array}$ & $\begin{array}{c}\text { Delta } \\
\text { Tocopherols }\end{array}$ \\
\hline $\begin{array}{l}\text { Linear range } \\
(\mu \mathrm{g} / \mathrm{mL})\end{array}$ & $1.25-200$ & $1.25-200$ & $1.25-200$ & $1.25-200$ \\
& & & & \\
Slope & 19.902 & 23.201 & 24.910 & 40.058 \\
& & & & \\
Intercept & 25.142 & 34.558 & 33.033 & 61.229 \\
S.D. of Slope & 0.009 & 0.012 & 0.007 & 0.003 \\
S.D. of Intercept & 0.429 & 0.453 & 0.332 & 0.442 \\
R.S.D of Slope & 0.049 & 0.054 & 0.028 & 0.008 \\
(\%) & & & & \\
R.S.D of & 1.709 & 1.309 & 1.006 & 0.721 \\
Intercept $(\%)$ & 0.9998 & 0.9997 & 0.9997 & 0.9997 \\
R & 0.034 & 0.023 & 0.023 & 0.045 \\
LOD $(\mu \mathrm{g} / \mathrm{mL})$ & 0.113 & 0.075 & 0.076 & 0.148 \\
LOQ $(\mu \mathrm{g} / \mathrm{mL})$ & & & & \\
\hline
\end{tabular}

The injection repeatability and extraction reproducibility for the proposed method were studied at $12.5 \mu \mathrm{g} / \mathrm{mL}$ and $0.100 \mu \mathrm{g} / \mathrm{mL}$ concentration level for each compound using six replicate determinations through the same day. The repeatability was calculated for retention times of analytes, too. The values of injection repeatability of areas and retention times and values of extraction reproducibility of analytes were shown in Table 3.

Table 3: Injection repeatability of areas and retention times and values of extraction reproducibility of analytes for proposed HPLC-FLD methods.

\begin{tabular}{ccccc}
\hline & $\begin{array}{c}\text { Alpha- } \\
\text { Tocopherols }\end{array}$ & $\begin{array}{c}\text { Beta- } \\
\text { Tocopherols }\end{array}$ & $\begin{array}{c}\text { Gamma- } \\
\text { Tocopherols }\end{array}$ & $\begin{array}{c}\text { Delta- } \\
\text { Tocopherols }\end{array}$ \\
\hline $\begin{array}{c}\text { Injection repeatability } \\
\text { mean area (mAU*s) }\end{array}$ & 298.44 & 340.74 & 370.08 & 617.70 \\
$\begin{array}{c}\text { Injection repeatability } \\
\text { (R.T for analytes) }\end{array}$ & 7.949 & 14.663 & 16.184 & 27.512 \\
S.D of area & 1.87 & 2.39 & 2.10 & 2.47 \\
S.D of R.T. & 0.07 & 0.17 & 0.18 & 0.34 \\
RSD of area & 0.63 & 0.70 & 0.57 & 0.40 \\
RSD of RT & 0.91 & 1.17 & 1.14 & 1.23 \\
Reproducibility of & 100.96 & 101.04 & 100.87 & 100.59 \\
analytes & 0.62 & 0.70 & 0.17 & 0.35 \\
SD & 0.61 & 0.69 & 0.17 & 0.35 \\
RSD & & & & \\
\hline
\end{tabular}

The accuracy parameters of methods were studied at three concentration levels for each compound with three replicate injections. The recovered concentrations were calculated using the calibration equations and recoveries of isomers showed that the method was acceptable for determination of the tocopherols in the seed oils (Table 4). 
Table 4: Accuracy of proposed HPLC-FLD methods at three different concentrations.

\begin{tabular}{lllll}
\hline $\begin{array}{l}\text { Recovery } \\
\mathbf{m g} / \mathbf{k g}\end{array}$ & $\begin{array}{l}\text { Alpha- } \\
\text { Tocopherol } \\
\text { (mean } \pm \text { SD) }\end{array}$ & $\begin{array}{l}\text { Beta- } \\
\text { Tocopherol } \\
\text { (mean } \pm \text { SD) }\end{array}$ & $\begin{array}{l}\text { Gamma- } \\
\text { Tocopherol } \\
\text { (mean } \pm \text { SD) }\end{array}$ & $\begin{array}{l}\text { Delta- } \\
\text { Tocopherol } \\
\text { (mean } \pm \text { SD) }\end{array}$ \\
\hline 80 & $99.61 \pm 0.12$ & $100.36 \pm 0.12$ & $98.76 \pm 0.39$ & $100.64 \pm 0.40$ \\
100 & $100.76 \pm 0.81$ & $101.33 \pm 0.83$ & $100.85 \pm 0.19$ & $100.44 \pm 0.31$ \\
120 & $100.80 \pm 0.28$ & $100.83 \pm 0.37$ & $100.10 \pm 0.11$ & $99.42 \pm 0.09$ \\
\hline
\end{tabular}

The specificity is defined as the ability to contact clearly with the analyte in the presence of components that may be expected to be present, such as degradation products and matrix components (ICH, 2016). Table 5 shows resolution (RS), tailing factor ( $T$ ), and theoretical plate number $(\mathrm{N})$ values of all tocopherols.

Table 5: Resolution, tailing factor, and theoretical plate number of tocopherols.

\begin{tabular}{lllll}
\hline & $\begin{array}{l}\text { Alpha- } \\
\text { Tocopherol }\end{array}$ & $\begin{array}{l}\text { Beta- } \\
\text { Tocopherol }\end{array}$ & $\begin{array}{l}\text { Gamma- } \\
\text { Tocopherol }\end{array}$ & $\begin{array}{l}\text { Delta- } \\
\text { Tocopherol }\end{array}$ \\
\hline RT $(\min )$ & 7.949 & 14.663 & 16.184 & 27.512 \\
$\mathbf{R s}$ & 11.83 & 14.94 & 2.66 & 14.25 \\
$\mathbf{T}$ & 1.149 & 1.154 & 1.155 & 1.154 \\
$\mathbf{N}$ & 7809 & 10597 & 10755 & 11596 \\
\hline
\end{tabular}

Tocopherol isomers have shown good RS that means the tocopherol peaks were separated from other isomers. Good peaks were obtained from the proposed method for quantification of tocopherols according to $\mathrm{T}$ and $\mathrm{N}$ values.

\section{Measurement Uncertainty for two methods}

The standard GC method was applied according to IOC for fatty acid methyl esters. In this study, uncertainty of measurement (u) was calculated for both HPLC and the GC method. The same sample was prepared according to sample preparation procedure for each analysis and then injected to the GC and HPLC systems. The samples were analyzed for two replicate determinations of each compound, that is to say, two samples each day for ten consecutive days with measurement every day. The results were given as mean $\pm \mathrm{u}$ for some selected fatty acid methyl esters and all tocopherol isomers in Table 6.

Uncertainty of measurement was necessary for the reliability of the results and routine analysis laboratories.

\section{Application of the developed method}

The optimized methods were applied to fifteen cold pressed seed oils. The representative chromatograms were obtained from the assayed seed oils were illustrated in Figures 1 and 2. Hazelnut chromatogram were selected as an example. 
Table 6: Uncertainty of measurements of tocopherols and some selected fatty acids. (Fatty acids were expressed as \%, tocopherols were expressed as $\mu \mathrm{g} / \mathrm{mL}$ )

\begin{tabular}{llll} 
Analytes & Mean $\pm \mathbf{u}$ & Analytes & Mean $\pm \mathbf{u}$ \\
\hline Arachidic Acid & $0.43 \pm 0.10$ & Palmitic Acid & $11.80 \pm 2.12$ \\
Behenic Acid & $0.20 \pm 0.08$ & Stearic Acid & $3.66 \pm 0.2$ \\
Gondoic Acid & $0.38 \pm 0.12$ & Alpha TOH & $119.72 \pm 6.44$ \\
Linoleic Acid & $21.41 \pm 0.59$ & Beta TOH & $106.56 \pm 5.20$ \\
Linolenic Acid & $2.24 \pm 0.19$ & Gamma TOH & $107.52 \pm 4.78$ \\
& & &
\end{tabular}

Since all tocopherols were present, the hazelnut oil chromatogram was chosen as the sample chromatogram.

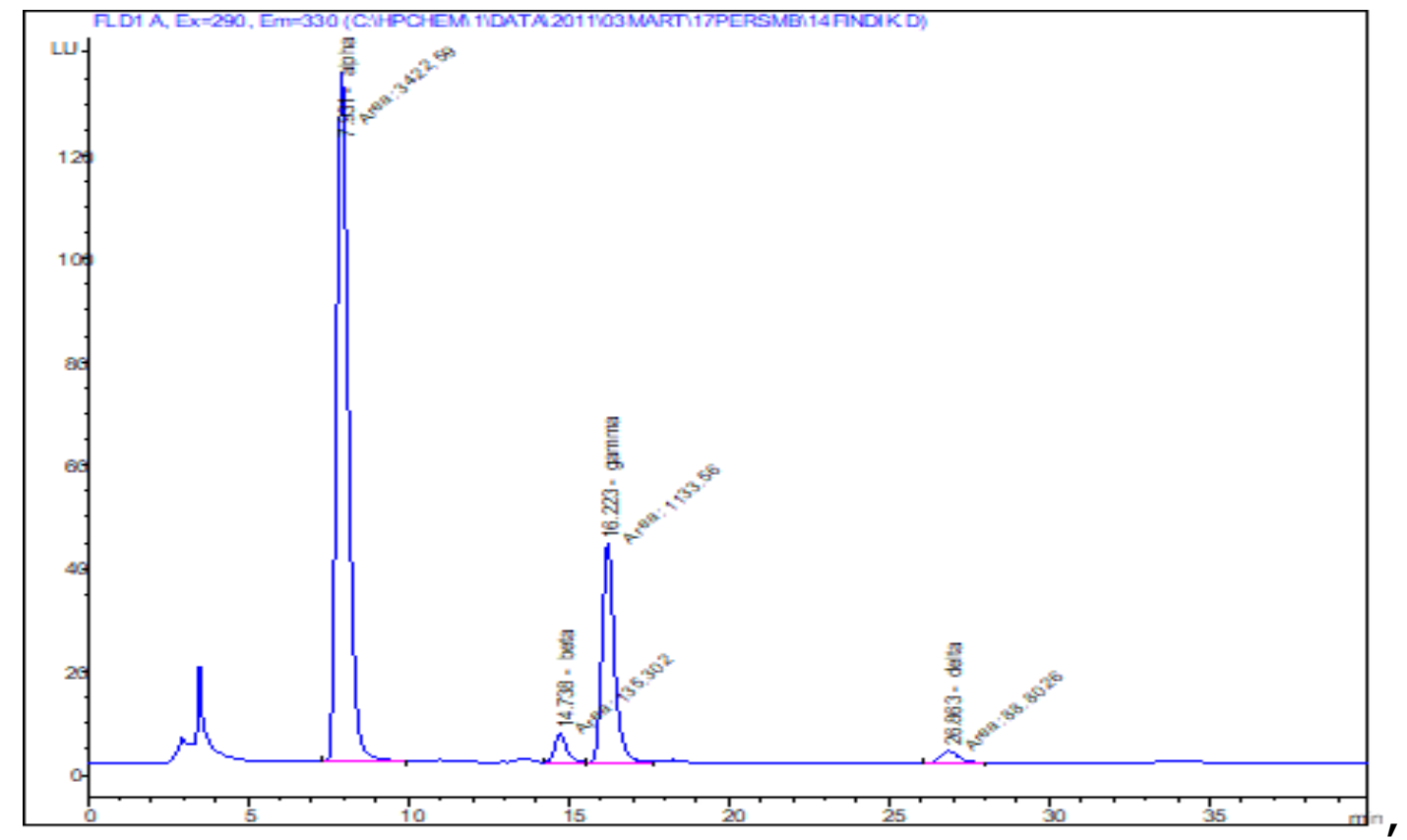

Figure 1: HPLC-FLD chromatogram of cold-pressed hazelnut seed oil for tocopherols. 


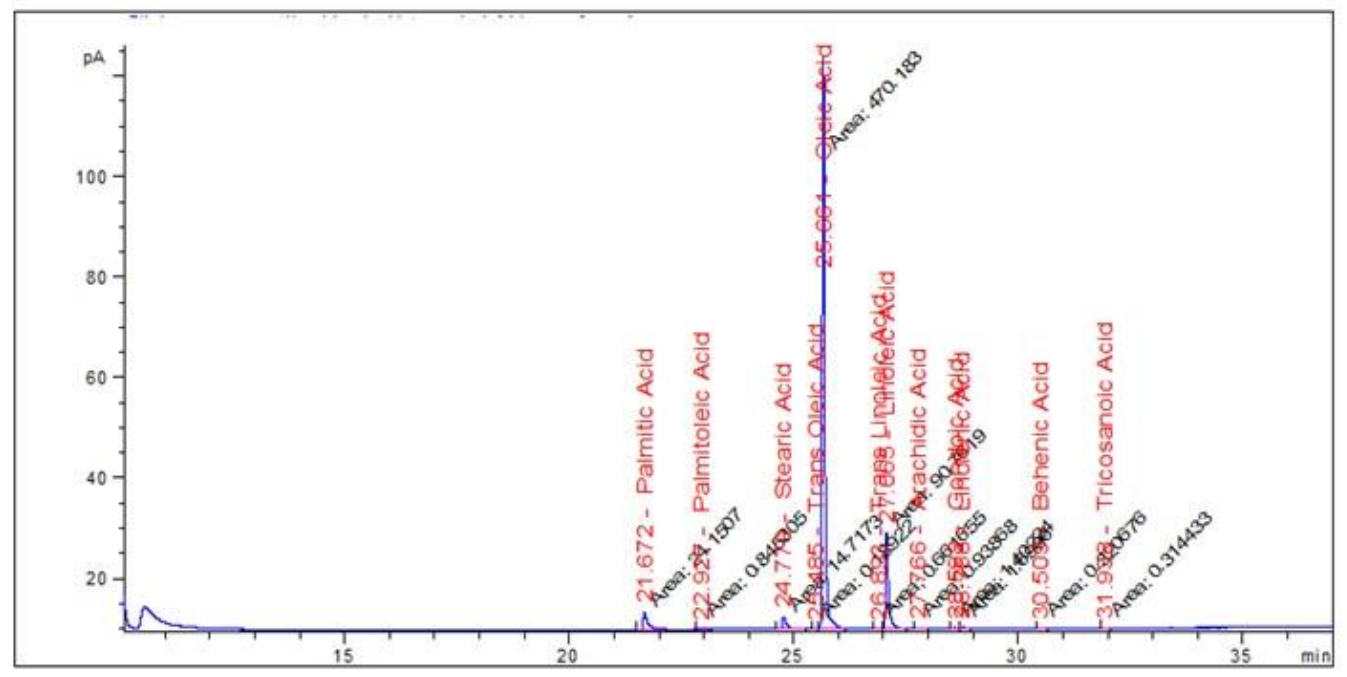

Figure 2: GC-FID chromatogram of cold-pressed hazelnut seed oils for fatty acid methyl esters.

It can be concluded that the acceptable analytical performance of the proposed method supports its appropriateness for the routine analysis to determine tocopherols in seed oils for quality controls. Table 7 shows tocopherol content of fifteen cold-pressed seed oils.

Table 7: Amount of tocopherols for fifteen cold-pressed seed oils. Tocopherols were expressed as $\mu \mathrm{g} / \mathrm{mL}$.

\begin{tabular}{lllll}
\hline Oil/Tocopherols & $\begin{array}{l}\text { Alpha- } \\
\text { Tocopherol }\end{array}$ & $\begin{array}{l}\text { Beta- } \\
\text { Tocopherol }\end{array}$ & $\begin{array}{l}\text { Gamma- } \\
\text { Tocopherol }\end{array}$ & $\begin{array}{l}\text { Delta- } \\
\text { Tocopherol }\end{array}$ \\
\hline Sunflower Seed & $920.37 \pm 1.86$ & $37,3 \pm 1.25$ & $1.23 \pm 0.15$ & nd \\
Poppy Seed & $32.86 \pm 2.62$ & nd & $276.07 \pm 6.30$ & $1.87 \pm 0.21$ \\
Sesame Seed & $53.73 \pm 1.50$ & nd & $482.33 \pm 2.65$ & $6.86 \pm 0.21$ \\
Pomegranate Seed & $72.37 \pm 2.35$ & nd & $2625 \pm 6.35$ & $61.33 \pm 1.93$ \\
Nettle Seed & $19.4 \pm 0.62$ & nd & $573.03 \pm 4.09$ & $9.16 \pm 0.35$ \\
Flax Seed & $7.46 \pm 0.35$ & nd & $434 \pm 2.56$ & $4.26 \pm 0.21$ \\
Peanut & $114.7 \pm 2.45$ & $1.36 \pm 0.15$ & $45.5 \pm 0.75$ & $9.92 \pm 0.09$ \\
Pumpkin Seed & $25.73 \pm 1.21$ & nd & $678 \pm 3.20$ & $10.01 \pm 0.08$ \\
Walnut & $27.23 \pm 0.51$ & nd & $417.73 \pm 3.14$ & $37.36 \pm 0.66$ \\
Wheat germ & $2556.07 \pm 10.26$ & $1061.53 \pm 6.80$ & $89.46 \pm 1.14$ & nd \\
Hazelnut & $1218.83 \pm 7.41$ & $42.20 \pm 0.35$ & $320.43 \pm 2.11$ & $13.87 \pm 0.31$ \\
Grape Seed & $82.37 \pm 1.32$ & $0.27 \pm 0.01$ & $83.84 \pm 1.42$ & $20.24 \pm 0.41$ \\
Black Cumin Seed & $58.13 \pm 1.88$ & nd & $185.34 \pm 3.05$ & nd \\
Canola & $235.12 \pm 3.17$ & nd & $412.86 \pm 5.07$ & nd \\
Safflower Seed & $1063.25 \pm 4.96$ & $18.41 \pm 0.64$ & $45.56 \pm 1.18$ & nd \\
\hline
\end{tabular}

$\mathrm{n}=3$ mean \pm SD SD: standard deviation nd: not detected.

The wheat germ oil was found to be with the highest $\alpha$-tocopherol amount among the other cold-pressed oils. Wheat germ oil itself has the highest tocopherol content of all vegetable 
oils up to about $2,500 \mathrm{mg} / \mathrm{kg}$ and also the highest content of a-tocopherol $(33,34)$. These effects are attributed to the high concentration of bioactive compounds present in the germ.

In this study, the highest a-tocopherol level was found in the wheat germ oil as 1218 $\mathrm{mg} / \mathrm{kg}$. The hazelnut oil had the next highest level among the other seed oils and it could be considered compatible with other previous studies $(35,36)$. The safflower and sunflower oils were also found with a high content of a-tocopherol among other fifteen different types of cold-pressed oil. In another study, three types of tocopherols were found in safflower oil in various amounts; a-tocopherol, $\beta$-tocopherol, and $y$-tocopherol ranging from 46.05 to $70.93 \mathrm{mg} / 100 \mathrm{~g}, 0.85$ to $2.16 \mathrm{mg} / 100 \mathrm{~g}$ and trace amount to $0.45 \mathrm{mg} / 100 \mathrm{~g}$ of oils, respectively (37). For the sunflower seeds, Świgło et al. (2007) found similar results by the highest level of a-tocopherol among other tocopherols (38). The differences between the amounts could be considered to be from the raw materials 'countries of origin, different cultivars, geographical and growing conditions. The pomegranate seed oils have the highest amount gamma tocopherols and delta tocopherols. All seed oils have alpha and gamma tocopherols which have shown that seeds' oils could be used for human health protection (39).

The seed oils were classified into three groups according to their fatty acid compositions with a high oleic acid, linoleic acid and others which differ in terms of other fatty acids. In the study, as shown in the Supplementary Material (SM1a), oleic acid contents of hazelnut oil, canola oil, peanut oil, sesame seed oil, and pumpkin seed oil were found with the

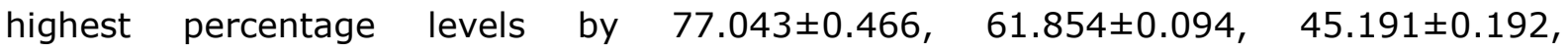
$38.374 \pm 0.075,36.481 \pm 0.200$ respectively. These data were found dissimilar with the other studies about general fatty acid composition of mentioned oil $(40,41)$.

Linoleic acid content of the fifteen different oils (SM1b) has been evaluated and poppy seed oil, nettle seed oil, sunflower seed oil, grape seed oil and safflower oil were found to have the highest percentage rates with 71.920 $\pm 0.949,66.624 \pm 0.231,64.952 \pm 0.312$, $63.455 \pm 0.793,58.217 \pm 0.365$ respectively. These results were also similar with the other studies $(42,37,12)$.

Among the other fatty acid compositions, linolenic acid content were found very high for flax seed oil $(54,77 \%)$ and walnut oil $(11,33 \%)$ as expected from other studies $(43,12$, 44). Besides, pomegranate seed oil distinctly has punicic acid at the rate of $80,92 \%$. Considering the other studies showing a range 55.8 to $86.6 \%$, our results might be considered within a high level (45-47). The wheat germ was shown to have differences 
with a palmitic acid ratio by $16,60 \%$ as it could be seen in SM1c, agreeing with the other studies $(48,49)$.

\section{Principal Component Analysis (PCA)}

As stated above, 15 different seed oil samples were analyzed to determine their tocopherol contents and fatty acid methyl esters. Thus, classification of the samples according to some selected parameters was performed with PCA. The punicic acid was not evaluated because only pomegranate seed oil has this fatty acid. Figure 3, the score plots of all data of tocopherols and fatty acid methyl esters were indicated in the one main group according to PC1 and PC2.

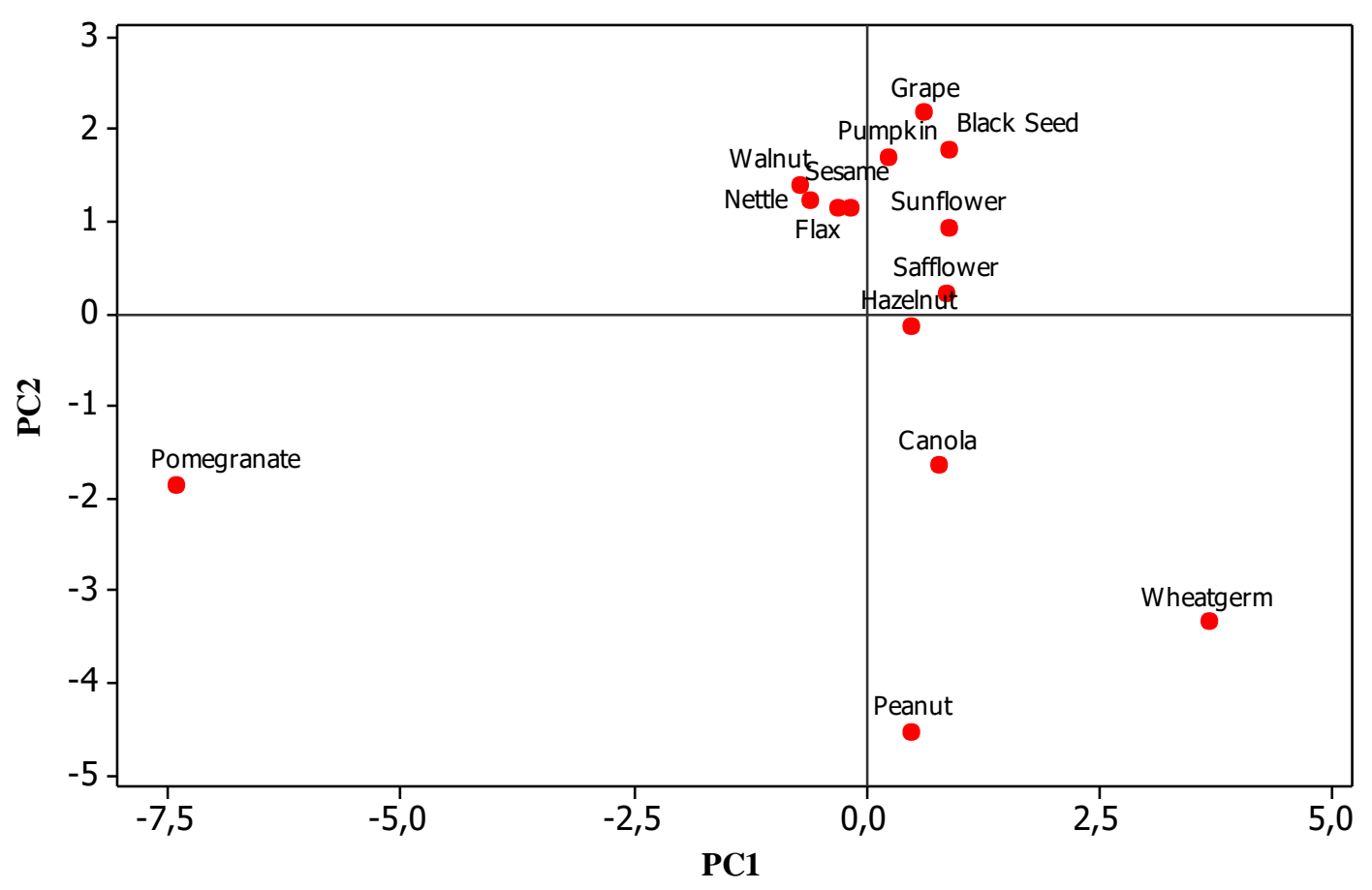

Figure 3: Score plot of FAME and tocopherols.

The pomegranate seed, canola, wheat germ, peanut oils were separated from all other seed oils.

When the PCA was accomplished, the results of the modelling power analysis was showed that tocopherols and minor fatty acids were the most effective variables to discriminate the seed oils from the others, as seen in the loading plot in Figure 4. 


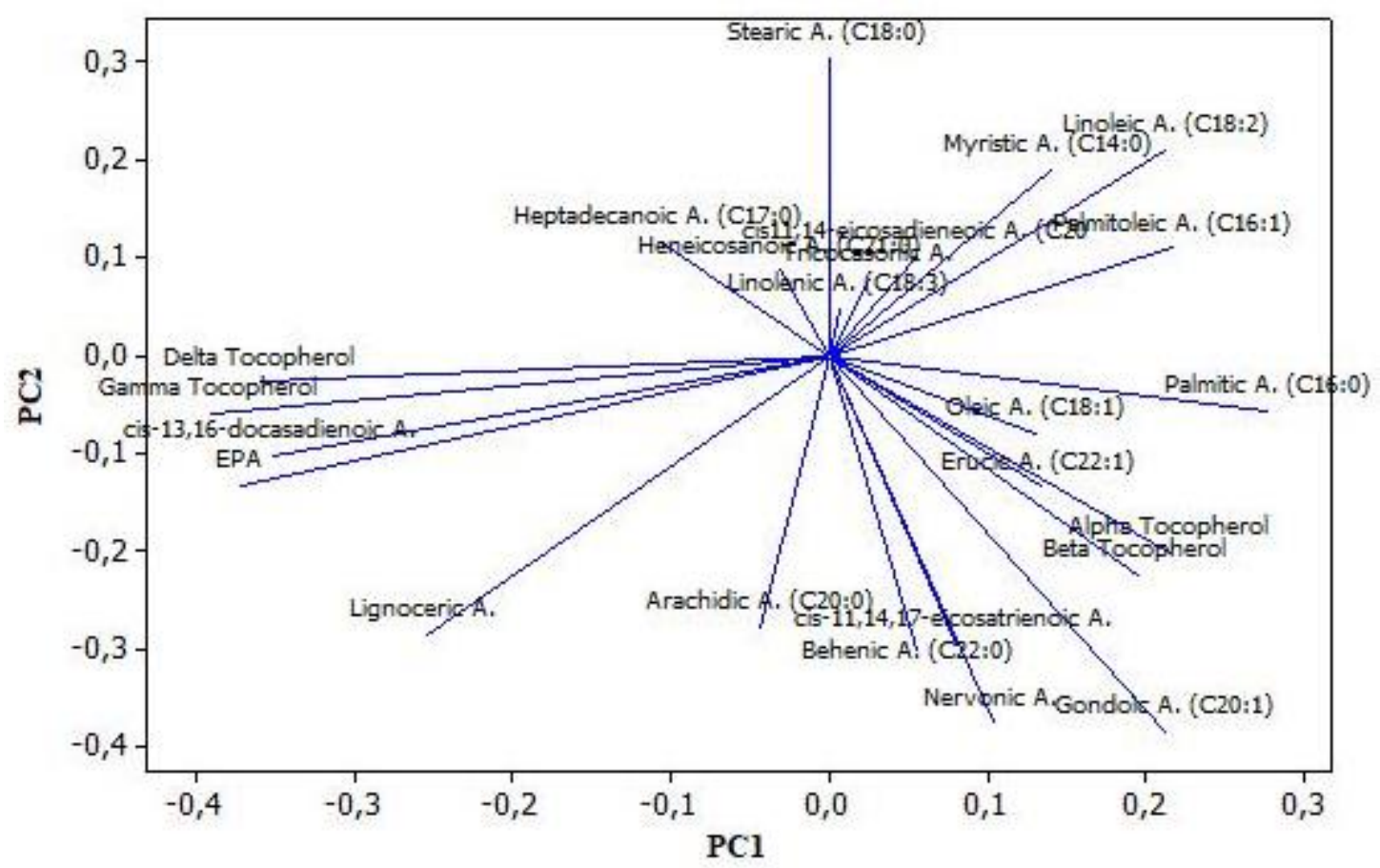

Figure 4: Loading plot of FAME and tocopherols.

The delta and gamma tocopherols, cis-13,16-docosadienoic acid, and EPA play an important role on the differentiation of pomegranate seed oil. The alpha and beta tocopherols, oleic acid and palmitic acid differentiate wheat germ oil from other seed oils. Minor fatty acids have a role in the differentiation of peanut oils. They are gondoic, nervonic, behenic, arachidic and cis-11,14,17-eicosatrienoic acids. The grape seed, walnut, pumpkin seed, sesame seed, nettle seed, flax seed, black cumin seed, safflower seed, sunflower seed, and hazelnut oils were distinguished with the effect of linoleic and linolenic acid.

\section{CONCLUSION}

To the best of our knowledge, this is the first report that describes the quantitative determination of fatty acid methyl esters and tocopherols in fifteen cold-pressed oils. The major parameters of cold-pressed seed oils were shown by using principal component analysis.

This study proposes a quick and more practical methodology regarding conventional applications, especially for tocopherol analysis, for raw materials evaluation, and the acceptance step to determine, where time matters, the appropriate raw material for the intended usage. This is also applicable during routine analysis, quality control, and stability 
studies of the last products like soft gelatin capsules containing cold-pressed oils. Additionally, the methodology will help with the classification of the quality of cold-pressed oils in the market. The proper utilization of the methodology to analyze and control quality can determine to which the most appropriate applications different oils should be used.

For further research projects and the manufacturing process for industry, these results were shown that fifteen different oils from Turkey's different regions might be preferred as a natural source of antioxidants and essential fatty acids like omega 3, 6, 9, and some specific fatty acids components like punicic acid. All the above-mentioned seeds from the region can be interesting and useful either for applications of food, pharmaceutical, cosmetic, or chemical industries. The cold-pressed oils from the area can be considered as a valuable source for natural antioxidants, poly-unsaturated fatty acids and some specific fatty acids. Also, the applied and validated method can help the industry for a more practical approach for quality analysis.

\section{ACKNOWLEDGMENTS}

This work was supported by the Ege University, Drug Research and Pharmacokinetic Development and Applied Center, (ARGEFAR). The authors wish to thank the Zade Vital Pharmaceuticals Inc. for providing cold-pressed oils.

\section{COMPLIANCE WITH ETHICAL STANDARDS}

The authors declare that they have no conflict of interest.

\section{REFERENCES}

1. Teh SS, Morlock GE. Effect-directed analysis of cold-pressed hemp, flax and canola seed oils by planar chromatography linked with (bio)assays and mass spectrometry. Food Chemistry. $2015 ; 187: 460-468$.

2. Topkafa M. Evaluation of chemical properties of cold pressed onion, okra, rosehip, safflower and carrot seed oils: triglyceride, fatty acid and tocol compositions. Analytical Methods 2016;8:42204225.

3. Yu LL, Zhou KK, Parry J. Antioxidant properties of cold-pressed black caraway, carrot, cranberry, and hemp seed oils. Food Chemistry. 2005;91:723-729. 
4. Teh SS, Birch J. Physicochemical and quality characteristics of cold-pressed hemp, flax and canola seed oils. Journal of Food Composition and Analysis. 2013;30:26-31.

5. Van Hoed V, Barbouche I, De Clercq N, Dewettinck K, Slah M, Leber E, Verhé R. Influence of filtering of cold pressed berry seed oils on their antioxidant profile and quality characteristics. Food Chemistry. 2011;127:1848-1855.

6. Nam UG, Nam D. Some physicochemical properties, fatty acid composition and antimicrobial characteristics of different cold-pressed oils. La rivista italiana delle sostanze grasse, XCII, 2016;187200.

7. Lampi, A.M., ve Heinonen, M. Berry seed and grapeseed oils, Gourmet and health-promoting specialty oils, In R. A. Moreau A. Kamal-Eldin, AOCS Press, Urbana, IL, 2009:215-236.

8. Yilmaz E, Aydeniz B, Güneşer O, Arsunar ES. Sensory and physico-chemical properties of cold press-produced Tomato (Lycopersicon esculentum L.) Seed Oils. Journal of American Oil Chemist Society. 2015;92:833-842.

9. Thanonkaew A, Wongyai S, McClements DJ, Decker a E. Effect of stabilization of rice bran by domestic heating on mechanical extraction yield, quality, and antioxidant properties of cold-pressed rice bran oil (Oryza saltiva L.). LWT - Food Science and Technology. 2012;48:231-236.

10. Gharibzahedi SMT, Mousavi SM, Hamedi M, Rezaei K, Khodaiyan F. Evaluation of physicochemical properties and antioxidant activities of Persian walnut oil obtained by several extraction methods. Industrial Crops and Products. 2013;45:133-140.

11. Lutterodt H, Slavin M, Whent M, Turner E, Yu L. Fatty acid composition, oxidative stability, antioxidant and antiproliferative properties of selected cold-pressed grape seed oils and flours. Food Chemistry. 2011;128:391-399.

12. Bozan B, Temelli F. Chemical composition and oxidative stability of flax, safflower and poppy seed and seed oils. Bioresource and Technology.2008;99:6354-6359.

13. Kozłowska M, Gruczyńska E, Ścibisz I, Rudzińska M. Fatty acids and sterols composition, and antioxidant activity of oils extracted from plant seeds. Food Chemistry. 2016;213:450-456.

14. Gumus ZP, Guler E, Demir B, Barlas FB, Yavuz M, Colpankan D, Senisik a. M, Teksoz S, Unak P, Coskunol H, Timur S. Herbal infusions of black seed and wheat germ oil: Their chemical profiles, in vitro bio-investigations and effective formulations as Phyto-Nanoemulsions. Colloids and Surfaces B: Biointerfaces. 2015;133:73-80

15. Ağ Şelecỉ D, Gümüş ZP, Yavuz M, Şeleci M, Bongartz R, Stahl F, Coşkunol H, Timur S. Scheper $T$. A case study on in vitro investigations of the potent biological activities of wheat germ and black cumin seed oil. Turkish Journal of Chemistry. 2015;39:801-812.

16. Argon Ustun Z, Gökyer A. Determination of physicochemical properties of Nigella sativa seed oil from Balıkesir region, Turkey. Chemical and Process Engineering Research. 2016; 41:43-46.

17. Abdallah IB, Tlili N, Martinez-Force E, Rubio AGP, Perez-Camino MC, Albouchi A, Boukhchina S. Content of carotenoids, tocopherols, sterols, triterpenic and aliphatic alcohols, and volatile compounds in six walnuts (Juglans regia L.) varieties. Food Chemistry. 2015;173:972-978.

18. Butinar B, Bučar-Miklavčič M, Mariani C, Raspor P. New Vitamin E isomers (gamma-tocomonoenol and alpha-tocomonoenol) in seeds, roasted seeds and roasted seed oil from the Slovenian pumpkin variety "Slovenska golica. Food Chemistry. 2011;128:505-512.

19. Parcerisa J, Richardson DG, Rafecas M, Codony R, Boatella J. Fatty acid, tocopherol and sterol content of some hazelnut varieties (Corylus avellana L.) harvested in Oregon (USA). Journal of Chromatography A. 1998;805:259-268.

20. Guler E, Barlas FB, Yavuz M, Demir B, Gumus ZP, Baspinar Y, Coskunol H, Timur S, Bio-active nanoemulsions enriched with gold nanoparticle, marigold extracts and lipoic acid: In vitro investigations. Colloids and Surfaces B: Biointerfaces. 2014;121:299-306. 
21. Saldeen K, Saldeen T. Importance of tocopherols beyond a-tocopherol: evidence from animal and human studies. Nutrition Research. 2005;25:877-889.

22. Fine F, Brochet C, Gaud M, Carre P, Simon N, Ramli F, Joffre F. Micronutrients in vegetable oils: The impact of crushing and refining processes on vitamins and antioxidants in sunflower, rapeseed and soybean oils. European Journal of Lipid Science and Technology. 2016;118:680-697.

23. Wall R, Ross RP, Fitzgerald GF, Stanton C. Fatty acids from fish: the anti-inflammatory potential of long-chain omega-3 fatty acids. Nutrition Reviews. 2010:68(5):280-289.

24. Patterson E, Wall R, Fitzgerald GF, Ross RP, Stanton C. Health Implications of High Dietary Omega-6 Polyunsaturated Fatty Acids Corporation Journal of Nutrition and Metabolism, 2012;Article ID 539426:16.

25. Das Un. Essential fatty acids: biochemistry, physiology and pathology. Biotechnology Journal, $2006 ; 1(4): 420-439$.

26. Owen RW, Mier W, Giacosa A. Phenolic compounds and squalene in olive oils: the concentration and antioxidant potential of total phenols, simple phenols, secoiridoids, lignans and squalene. Food Chemical Toxicology. 2000;38:647-659.

27. Visioli F, Galli C, Galli G, Caruso D. Biological activities and metabolic fate of olive oil phenols. European Journal of Lipid Science and Technology. 2002;104:677-684.

28. Waterman E, Lockwood B. Active Components and Clinical Applications of Olive Oil. Alternative Medicine Review. 2007;12(4):331-42.

29. AOCS, Lipid Library, http://lipidlibrary.aocs.org/ , Last Accessed: June, (2017)

30. IOC, http://www.internationaloliveoil.org COI/T.20/Doc. No 33. Last Accessed: June, (2017)

31. AOCS Official Method Ce 8-89 Determination of tocopherols and tocotrienols in vegetable oils and fats by HPLC.

32. ICH, International Conference on Harmonization Guidelines (ICH Q2B, validation of analytical procedures, methodology).

http://www.ich.org/products/guidelines/quality/quality-single/article/validation-of-analyticalprocedures-text-and-methodology.html, Last Accessed: June, (2017)

33. Dunford NT. Health benefits and processing of lipid-based nutritionals. Food Technology. 2001;55(11):38-44.

34. Piras A, Rosa A, Falconieri D, Porcedda S, Dessì MA, Marongiu B. Extraction of oil from wheat germ by supercritical CO2. Molecules. 2009;14:2573-2581.

35. Crews C, Hough P, Godward J, Brereton P, Lees M, Guiet S, Winkelmann W. Study of the main constituents of some authentic hazelnut oils. Journal of Agricultural and Food Chemistry. $2005 ; 53: 4843-4852$.

36. Ozdemir M, Ackurt F, Kaplan M, Yildiz M, Loker M, Gurcan T, Biringen G, Okay A, Seyhan FG. Evaluation of new Turkish hybrid hazelnut (Corylus avellana L.) varieties: Fatty acid composition, $\alpha-$ tocopherol content, mineral composition and stability. Food Chemistry. 2001;73:411-415.

37. Matthaus B, Özcan MM, Al Juhaimi FY. Fatty acid composition and tocopherol profiles of safflower (Carthamus tinctorius L.) seed oils. Natural Product Research. 2015; 29(2):193-6.

38. Gliszczyńska-Świgło A, Sikorska E, Khmelinskii I, Sikorski M. Tocopherol content in edible plant oils. Polish Journal of Food and Nutrition Sciences. $2007 ; 57: 4(A): 157-161$.

39. Ozturk Kirbay F, Geyik C, Guler E, Yesiltepe O, Gumus ZP, Odaci Demirkol D, Coskunol H, Timur $\mathrm{S}$. Testing of bioactive-nanovesicles on hepatotoxicity of atypical antipsychotics via digital holography. Colloids and Surfaces B: Biointerfaces. 2017;152:289-295. 
40. Nzikou JM, Matos L, Bouanga-Kalou G, Ndangui CB, Pambou-Tobi NPG, Oomah BD, Mazza G. Health benefits of phytochemicals from selected Canadian crops, TrAC - Trends in Analytical Chemistry. 1999;10:193-198.

41. Mitra P, Ramaswamy HS, Chang KS. Pumpkin (Cucurbita maxima) seed oil extraction using supercritical carbon dioxide and physicochemical properties of the oil. Journal of Food Engineering. 2009;95:208-213.

42. Guil-Guerreroa JL, Rebolloso-Fuentesa MM, Torija Isasab ME. Fatty acids and carotenoids from Stinging Nettle (Urtica dioica L.). Journal of Food Composition and Analysis. 2003;16:111-119.

43. Singh KK, Mridula D, Rehal J, Barnwal P. Flaxseed: a potential source of food, feed and fiber. Critical Review Food Science and Nutrition. 2011;51(3):210-22.

44. Comba A, Maestri DM, Berra MA, Garcia CP, Das UN, Eynard AD, Pasqualini ME. Effect of $\omega-3$ and $\omega-9$ fatty acid rich oils on lipoxygenases and cyclooxygenases enzymes and on the growth of a mammary adenocarcinoma model. Lipids in Health and Disease. 2010;9:112.

45. Fadavi A, Barzegar M, Azizi MH. Determination of fatty acids and total lipid content in oil seed of 25 pomegranates varieties grown in Iran. Journal of Food Composition and Analysis. 2006;19:676680.

46. Kaufman M, Wiesman Z. Pomegranate oil analysis with emphasis on MALDI-TOF/MS triacylglycerol fingerprinting. Journal of Agricultural and Food Chemistry. 2007;55:10405-10413.

47. Alcaraz-Mármol F, Nuncio-Jáuregui N, Calín-Sánchez A, Carbonell-Barrachina AA, Martínez JJ, Hernández F. Determination of fatty acid composition in arils of 20 pomegranates cultivars grown in Spain. Scientia Horticulturae. 2015;197:712-718.

48. Megahed MG. Study on stability of wheat germ oil and lipase activity of wheat germ during periodical storage. Agricultural and Biology Journal of North American. 2011;2(1):163-168.

49. Brandolini A, Hidalgo A. Wheat germ: not only a by-product. International Journal Food Science and Nutrition. 2012;63(1):71-74. 
